\title{
Aprendiendo de Europa
}

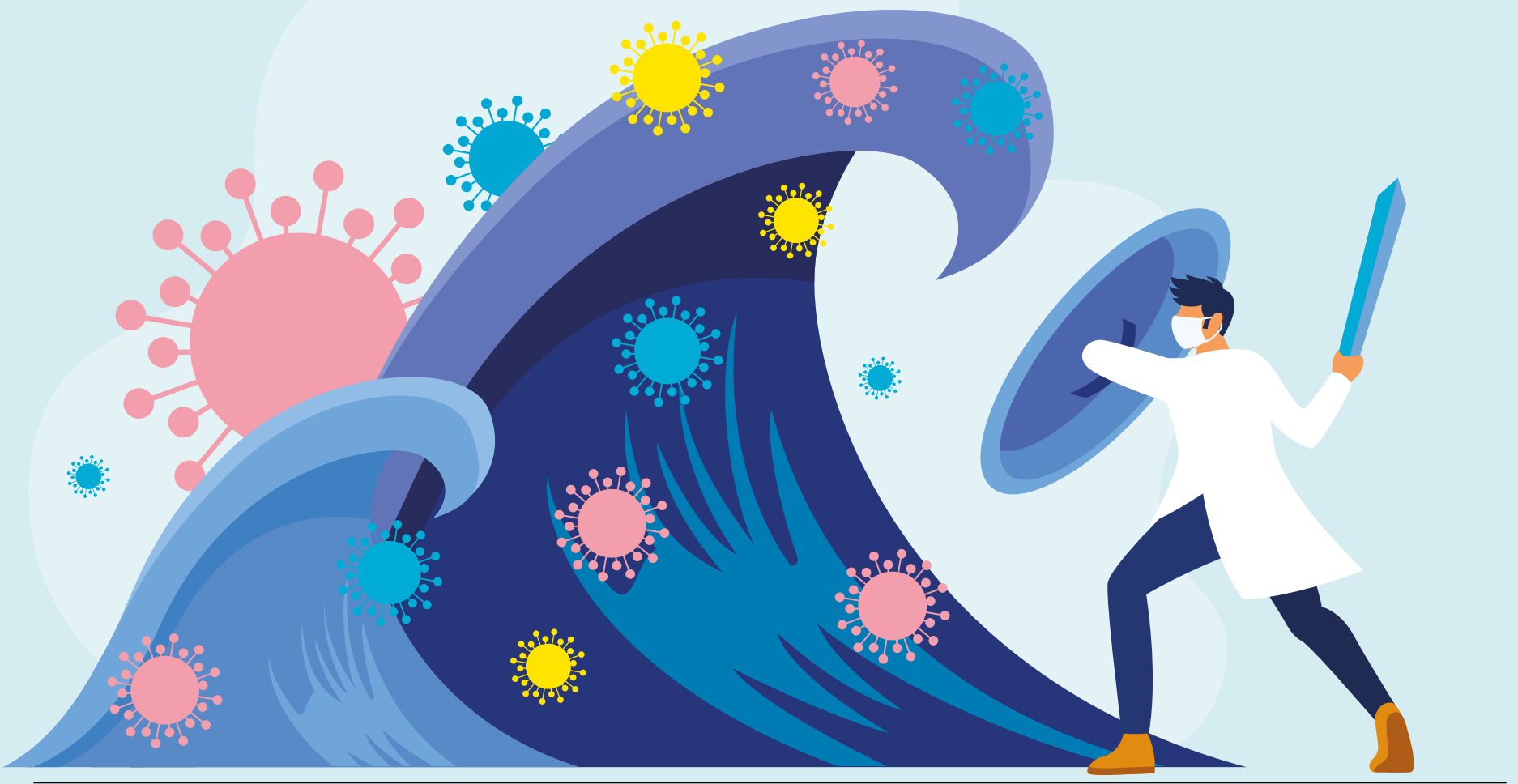

Por Eugenio Giolito, Ph.D. en Economía, University of Maryland, EE.UU. Director Magíster en Economía, FEN- UAH; y Marcela Perticará, Ph.D. en Economia, University of Texas A\&M, EE.UU. Directora Departamento de Economía, FEN- UAH.

$\mathrm{F}$ rente a la evolución de los contagios y la cercanía de las celebraciones de fin de año, el jueves 3 de diciembre se anunció un nuevo conjunto de medidas, entre las que está el hacer retroceder de fase a ocho comunas, algunas de las cuales pasan de la tres a la 2 y otras de fase 4 a fase 3 .

La reacción de las autoridades al aumento en los contagios, frente al ejemplo de lo que han sido las segundas olas en Europa, está fundada. Se teme que tengamos situaciones más dramáticas que las vividas a mediados de año, durante las semanas de peak de muertes.

Con todos los aciertos y desaciertos, Chile tuvo un enfrentamiento a la primera ola de la pandemia con relativamente buenos resultados, al menos en términos agregados. La Figura 1 nos muestra la comparación del exceso de mortalidad de Chile (en porcentaje) con el ocurrido en España, Italia y en EEUU.

Esta medida de exceso de muertes surge de comparar la morta- lidad en el 2020 con la de un año "normal" (en general el promedio de años anteriores) y se toma directamente de las estadísticas vitales y, por lo tanto, no está sujeta a la mayor o menor precisión en el diagnóstico, o a la intensidad en el testeo de los distintos países.

En la figura se pueden distinguir varias características diferenciada entre países. Se puede notar que tanto España como Italia muestran un "peak" muy pronunciado (de alrededor del 150 y $100 \%$ respectivamente), para caer hasta niveles cercanos a cero durante el verano europeo y eventualmente volver a subir durante el otoño. El caso de EEUU es diferente, con un "peak" mucho menor (alrededor de un $45 \%)$ y una caída mucho menos pronunciada, dado que el exceso de mortalidad nunca es inferior al $15 \%$, probablemente debido al paulatino desplazamiento de los contagios a través de los estados. La situación de Chile es más similar a la de EEUU, con un máximo del
$70 \%$ en junio y un descenso paulatino que tiene un piso del alrededor del $10 \%$ en todas las semanas analizadas hasta el momento.

El riesgo de que nuestro país vuelva al peak de las dos primeras semanas de junio, cuando el exceso de muertes estuvo en torno al $60 \%$ en el total del país, es alto dado el aceleramiento en la tasa de contagios registrado en los últimos días. La Región Metropolitana, es la que en junio tuvo un mayor exceso de muertes y la que, por las condiciones epidemiológicas actuales, tiene un riesgo más alto de tener

\section{Figura 1. Exceso de muertes año 2020. Chile versus países} seleccionados

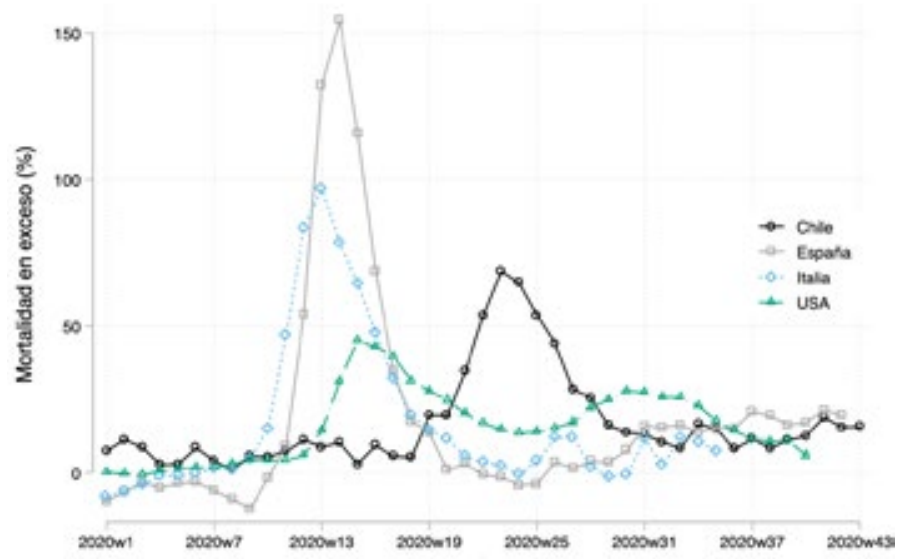

Fuente: Our World in data 
un rebrote complejo.

Para poner esta observación en perspectiva, la Figura 2 grafica la serie de exceso de muertes para la Región Metropolitana versus el resto del país. Ahí se puede ver que la tasa duplica la calculada para el total nacional. El peak se produce entre la segunda y tercera semana de junio, mientras que, en el resto de las regiones, no hay un peak tan pronunciado, sino que el indicador se mantiene en torno al $10-20 \%$ a partir de Junio.

Los grupos más afectados por la pandemia han sido la población de 60 y más (especialmente de 60-69 años) y los habitantes de comunas de bajo nivel socioeconómico en Región Metropolitana. Si durante junio del 2020 la tasa de mortalidad por cada mil habitantes fue un $50 \%$ más alta que la tasa de mortalidad en el año anterior, en el grupo etario 60-69 aumenta un $70 \%$, mientras que en comunas de bajo nivel socioeconómico crece un $120 \%$.

Es importante notar que cuando comparamos mes a mes las muertes entre el 2020 y un año "normal" ( $\sin$ COVID), hay que tener en cuenta dos factores que pueden cambiar radicalmente la interpretación de las estadísticas. Primero, si bien en Chile no está documentada que hubiera circulación de virus antes de marzo, la experiencia europea nos
Por un lado, la falta de diagnóstico oportuno a inicios de la pandemia puede haber llevado a que muchas muertes debidas a este virus fueran catalogadas por otras causas. Este es el caso fundamentalmente de muertes asociadas a diagnósticos respiratorios y/o cardiovasculares, dos complicaciones específicas del Covid-19. El virus puede también haber acelerado fallecimientos de personas con enfermedades crónicas o preexistentes. Nuevamente estas muertes aparecerán catalogadas como Covid-19, pero luego observaremos una caída en las muertes asociadas a estas patologías. Por el otro, las restricciones a la circulación podrían haber aumentado o reducido la muerte por otras causas si estas restricciones impidieron la atención oportuna o si redujeron las muertes por causas externas, como ser accidentes de tránsito.

En la Figura 3 se muestra, en columnas, el número absoluto de muertes atribuidas al COVID 19 en Chile por mes hasta octubre. Por lado, las líneas corresponden al exceso de muertes (en \%) con respecto al promedio de los años anteriores atribuidos a enfermedades respiratorias (no COVID), circulatorias, tumores y causas externas (accidentes, muertes violentas, etc.).

El exceso de muertes debido a
"Las políticas más permisivas adoptadas por muchos de los gobiernos europeos durante su verano han gatillado miles de muertes. Chile y Latinoamérica deberían aprender de esta lección, y trabajar en poner en práctica políticas y protocolos que permitan enfrentar la segunda ola con menores costos de muertes y enfermos, $y$ también con menores costos materiales"

dice que podríamos haber tenido algún tipo de circulación viral previo a esa fecha'. Y esto entonces debiera reflejarse en exceso de muertes antes de ese mes. En segundo lugar, al analizar las estadísticas de decesos y contagios no podemos soslayar el hecho de que este año la pandemia en sí y las intervenciones en la circulación afectaron la mortalidad por otras causas. las enfermedades respiratorias a principios de año está liderado fundamentalmente por personas por sobre los 60 años. Este patrón se repite por zona geográfica y/o nivel socioeconómico de la comuna. Es sugerente el mayor número de decesos atribuibles a causas respiratorias que se visualiza antes de marzo.

El exceso de muertes negativo

Figura 2. Exceso de muertes año 2020. Región Metropolitana vs. Resto del País

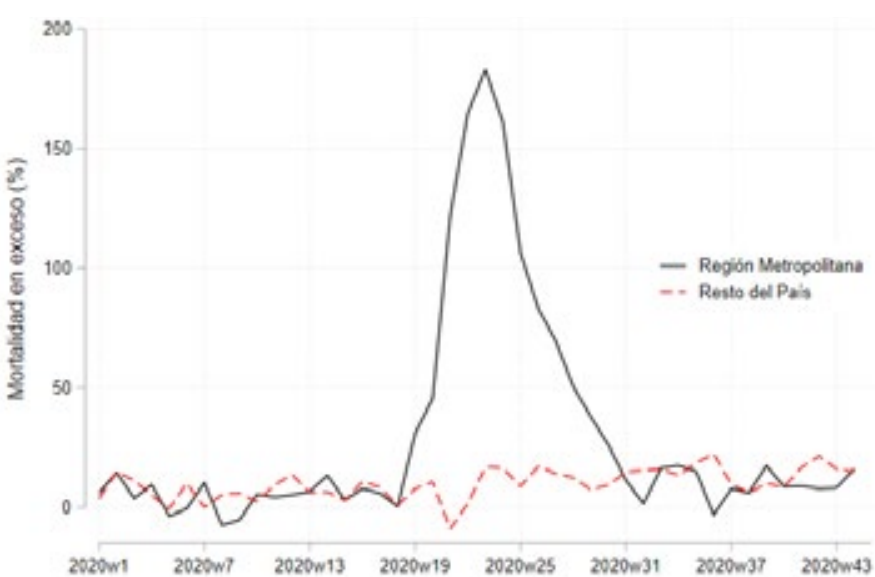

Fuente: DEIS

Figura 3. Mortalidad COVID 19 vs Mortalidad en exceso otras causas, Chile

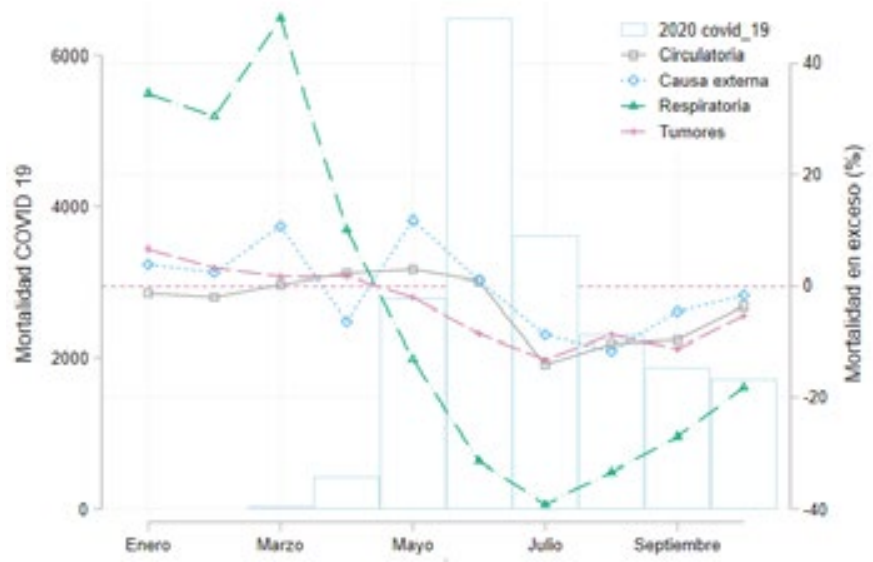

Fuente: DEIS

por otras causas a partir de mayo puede deberse a que personas con enfermedades terminales o crónicas fallecieron finalmente de Covid $y / o$ en el caso de enfermedades respiratorias y/o causas externas, el hecho de que el confinamiento redujo la exposición a otras causas.

Una segunda ola de Covid-19 está impactando Europa. A la última semana de noviembre el viejo continente había alcanzado un peak de muertes diarias similar al peak de abril, con varios países volviendo a fases de cuarentena parciales y totales. Las políticas más permisivas adoptadas por muchos de los gobiernos europeos durante su verano han gatillado miles de muer- tes. Chile, y Latinoamérica debería aprender de esta lección, y trabajar en poner en práctica políticas y protocolos que permitan enfrentar la segunda ola con menores costos de muertes y enfermos, y también con menores costos materiales.

Hay que enfrentar el hecho de que estamos aún lejos de tener una vacuna masiva. Hay que dejar de esconderse como el avestruz y reconocer que no podremos tener actividades normales en marzo, pero podemos prepararnos, tener mejores protocolos de trazabilidad y atención para los enfermos y para el funcionamiento para las actividades esenciales. $\mathbf{E}$ 